\title{
BMJ Open Prevalence of and factors associated with violations of a campus smoke-free policy: a cross-sectional survey of undergraduate students on a university campus in the USA
}

\author{
Sujith Ramachandran (D , ${ }^{1}$ Sandra Bentley, ${ }^{2}$ Ethan Casey, ${ }^{3}$ John P Bentley ${ }^{1}$
}

To cite: Ramachandran S, Bentley S, Casey E, et al. Prevalence of and factors associated with violations of a campus smoke-free policy: a cross-sectional survey of undergraduate students on a university campus in the USA. BMJ Open 2020;10:e030504. doi:10.1136/ bmjopen-2019-030504

- Prepublication history for this paper is available online. To view these files, please visit the journal online (http://dx.doi. org/10.1136/bmjopen-2019030504).

Received 17 March 2019 Revised 09 January 2020 Accepted 25 February 2020

A) Check for updates

(C) Author(s) (or their employer(s)) 2020. Re-use permitted under CC BY-NC. No commercial re-use. See rights and permissions. Published by BMJ.

${ }^{1}$ Pharmacy Administration, University of Mississippi, University, Mississippi, USA ${ }^{2}$ Pharmacy Practice, University of Mississippi, University, Mississippi, USA

${ }^{3}$ Pharmacy, Wal-Mart Stores Inc, Horn Lake, Mississippi, USA

Correspondence to Dr Sujith Ramachandran; sramacha@olemiss.edu

\section{ABSTRACT}

Objective The aim of this study is to estimate the prevalence of smoking behaviour on campus and to identify the key factors that influence adherence to a campus smoke-free policy.

Design \& participants This study employed a crosssectional, self-administered survey of undergraduate students at the University of Mississippi. A random sample of all available undergraduate classes was recruited for data collection. Students were provided a survey that included questions on demographics, alcohol use, smoking status, policy awareness, policy attitudes, smoking attitudes, policy support, barriers to policy success and policy violations.

Results The prevalence of past 30-day smoking was $23 \%$. More than $63 \%$ of current smokers report ever smoking on campus, but less than $10 \%$ ever received a warning or a ticket for their violation. Nearly all respondents $(92.5 \%)$ reported witnessing someone smoking on campus, and $22 \%$ reported witnessing someone receiving a ticket. Barriers to policy success include lack of reminders about the policy, lack of support from students and University administrators, and insufficient fines. Smoking behaviour (OR: 7.96; 95\% Cl: 5.13 to 12.36 ), beliefs about policy adherence (OR: 0.52 ; $95 \% \mathrm{Cl}: 0.40$ to 0.69 ), support for the policy (OR: 0.71 ; $95 \% \mathrm{Cl}: 0.55$ to 0.91 ) and attitudes against smoking behaviour (OR: $0.35 ; 95 \% \mathrm{Cl}: 0.25$ to 0.49 ) were all significantly associated with self-reported policy violations. Conclusions This study found that violations of the campus smoke-free policy were fairly frequent and the policy has been largely ineffective, indicating a need for other interventions. Approaches to improve adherence to the policy should address barriers such as reminders about the policy, better policy enforcement and support from the administration.

\section{INTRODUCTION}

Tobacco use is the single most preventable risk to human health, and is the direct cause of over 480000 deaths annually in the USA. ${ }^{1}$ Coordinated tobacco cessation efforts by several public health agencies and healthcare
Strengths and limitations of this study

- This study evaluated violations of a campus smokefree policy using campus-wide survey with a large number of respondents.

- This study assessed both self-reported policy violations and witnessing policy-violations by others, providing multiple perspectives on campus smoking behaviour.

- This study did not assess the effectiveness of the smoke-free policy and only includes data collected after the policy was implemented.

providers have successfully reduced the prevalence of smoking over the past $10-15$ years ${ }^{1-3}$. The prevalence of past 30-day cigarette and electronic cigarette (e-cigarette) smoking among US undergraduate students in the fall of 2015 was estimated to be $9.8 \%$ and $5.4 \%$, respectively. ${ }^{4}$ In the fall of 2018 , cigarette and e-cigarette use in this group was estimated to be $7.5 \%$ and $15.2 \%$, respectively. ${ }^{5}$ While the overall trend for cigarette smoking has been decreasing, there continues to be a small proportion who continue to smoke cigarettes, and the use of e-cigarettes among US college students has increased recently. Tobacco cessation efforts have targeted and continue to target the college student population through policies and interventions aimed at university campuses. The American College Health Association (ACHA), and other organisations, have advocated for prohibition of all tobacco use in indoor and outdoor environments on university campuses. ${ }^{6}$ This recommendation is supported by several studies that have demonstrated wide support for smokefree policies among university students and staff. $^{7-12}$ There has been a $300 \%$ increase in the use of smoke-free policies since 2010, with 
over 2000 universities implementing such policies, as of October, 2017. ${ }^{13}$

However, there is wide variation in the nature of these policies with many policies lacking clarity or combined with weak enforcement practices. ${ }^{14} 15$ Research into the effectiveness of campus smoke-free policies has found mixed results, with some universities reporting frequent policy violations and low compliance rates,${ }^{15-19}$ while some others report considerable reduction in smoking prevalence and exposure to secondhand smoke. ${ }^{18} 2021$ There is limited research on the factors affecting policy compliance and strategies to improve compliance to smoke-free policies on college campuses. ${ }^{22-24}$

The support for and effectiveness of smoking cessation policies can be influenced by societal antismoking norms, ${ }^{8} 2125$ smoking behaviour, ${ }^{8} 2126$ perceptions of peer tobacco use, ${ }^{21}$ and demographic variables such as gender and race. ${ }^{7}$ The current study utilises the framework proposed by Fong $e t$ al that guided the development of the International Tobacco Control policy evaluation project. ${ }^{27}$ This project has evaluated the impact of regulations, such as smoke-free policies, in several countries. The framework proposes that policies influence several policy-specific psychosocial variables-such as beliefs and attitudes, normalisation of beliefs, self-efficacy and intentions-which in turn influence policy-related outcomes, such as prevalence of smoking. Other variables, such as socio-demographics and smoking status, may moderate the relationship between psychosocial variables and policy outcomes. ${ }^{27}$ The current study focuses on psychosocial variables such as smoking attitudes, policy support and policy attitudes, and examines how the effects of these variables on policy outcomes are influenced by smoking status.

On the campus of the University of Mississippi, a smoke-free policy was implemented on 1 August 2012 to help reduce smoking prevalence. This policy prohibited all students, staff, employees and visitors from all forms of smoking which refers to inhaling, exhaling, burning, carrying or possessing any lighted tobacco product, including cigarettes, cigars, pipe tobacco and any other lit tobacco products, including e-cigarettes that emit smoke and littering of tobacco products. ${ }^{28}$ This policy affects all indoor and outdoor grounds including residence halls and personal vehicles. Since implementation, few steps have been taken to evaluate the prevalence of on-campus smoking and students' adherence to the policy. The specific aim of the current study was to evaluate adherence to the campus smoke-free policy, estimate the prevalence of on-campus smoking behaviour, identify the key factors that influence policy violations and measure barriers to successful implementation of a smoke-free policy. While the policy includes prohibition of several other behaviours such as littering and even possessing tobacco products, this study chose to focus specifically on smoking behaviour among college students, because they constituted a high-risk population for such violations.

\section{METHODS}

\section{Study design and procedures}

This study employed a cross-sectional, self-administered survey of undergraduate students at the University of Mississippi. The sampling frame included a list of all undergraduate classes offered in the fall semester of 2015 on the Oxford campus, as recorded by the University's Registrar. After excluding classes that were too small (less than four students), or were independent studies, a random sample of the remaining classes was chosen for inclusion in the study. Instructors of record for the chosen classes were contacted to request permission to distribute surveys in their classes. After obtaining instructor approval, the research team distributed a short survey at the beginning of each class. No additional eligibility criteria were implemented other than being enrolled in the class at the time of the survey. Student participation was voluntary, and no incentives were offered in return for participation. On opening the survey booklet, potential respondents were provided with information about the study, including contact details for the institutional review board (IRB). Respondents' completion of the survey constituted consent, as approved by the IRB. Students who were present in more than one participating class were requested to participate no more than once, to prevent repeat administration.

\section{Study measures}

The survey included questions on respondent demographics, alcohol use, smoking status, policy awareness, policy attitudes, smoking attitudes, policy support, barriers to policy success and policy violations. Respondent demographics and alcohol use questions were modelled after the ACHA's National College Health Assessment report. ${ }^{4}$ Current smoking status has been operationalised in a variety of ways in the extant literature. ${ }^{29}$ Among adults, current smoking status is defined by the Centers for Disease Control and Prevention as having smoked at least 100 cigarettes in a lifetime and smoking every day or on some days at the time of assessment. ${ }^{30}$ However, in a population of young adults, among whom new smokers, infrequent smokers and intermittent smokers are common, assessment of past 30-day smoking behaviour can be a better predictor of violation of smoke-free policies. Therefore, this study defined current smokers as those respondents who smoked at least one cigarette during the past 30 days. This characterisation of smoking behaviour was found applicable for the college student and young adult populations in previous studies. ${ }^{31-33}$

In order to measure awareness of the campus smoking policy, respondents were asked to identify the correct policy from a list of four options of varying stringency. Respondents were classified as being aware of the policy if they chose smoke-free campus (the correct policy), or tobacco-free campus, which is more rigorous than the actual policy. ${ }^{8}$ Respondents' attitudes about the policy were measured using six items, adapted from Chaaya $e t$ $a l$, using a five-point Likert response format. ${ }^{26}$ Measures 
assessing smoking attitudes (six items), support for the policy (four items) and barriers to policy success (11 items) were adapted from prior research and measured using five-point response formats. ${ }^{78263435}$

The variable of interest in this study, policy outcomes, was operationalised in two ways: (1) as a self-violation of the campus smoke-free policy and (2) witnessing violations of the policy by others. Respondents who self-reported smoking on campus and/or receiving a warning/ticket for smoking on campus were identified as violating the policy, ${ }^{26}$ creating a dichotomous variable. Respondents' witnessing of policy violations by others was assessed using four dichotomous items that asked if respondents had ever: witnessed someone smoking on campus, knew of someone who received a warning/ticket for smoking on campus, been exposed to secondhand smoke on campus and had to alter their walking route on campus in order to avoid smoke.

\section{Statistical analyses}

Data were collected via paper surveys and entered into Excel. Data entry was conducted by two independent researchers, and data were checked for discrepancies to prevent errors. IBM SPSS V.25 was used for data analysis. Descriptive analyses were conducted for all items in the survey. Bivariate relationships between current smoking status and other demographic variables were tested using $\chi^{2}$ tests for categorical variables and t-tests for continuous variables. Principal components analysis (PCA) was conducted to assess the dimensionality of the three multi-item measures that were used as predictors in subsequent regression analyses: policy attitudes, smoking attitudes and policy support. Logistic regression was conducted to predict self-reported violation of the policy using the demographic and psychosocial variables measured in the study as independent variables. Because the effects of demographics and psychosocial variables on the policy outcomes were expected to differ between current smokers and non-smokers, smoking status was introduced as a moderator of the effects of the hypothesised study predictors in the logistic regression model by including interaction terms. Descriptive statistics were used to summarise the prevalence of witnessing policy violations by others.

\section{Participant and public involvement}

There was no direct involvement of participants nor the public in the development, conceptualisation or conduct of the study, nor in the interpretation of the results. An overview of the study was presented at campus meetings, but results were not directly disseminated to individual study participants as the survey was conducted anonymously.

\section{RESULTS}

Forty-seven, out of a total of 94 invited instructors, agreed to the request for study participation. Survey administrators distributed copies of the surveys to 1704 students in 60 course sections. Fifty students were not eligible to participate either because they were less than 18 years old, or they had already completed the survey in a different class section. Of the remaining 1654 students, 1541 surveys were collected with at least one completed response, leading to a response rate of $93 \%$. After deleting responses that had missing responses on more than 30 out of the 63 items on the survey, analyses were conducted on 1512 responses. As seen in table 1, the sample was composed of nearly $60 \%$ women, $78 \%$ Caucasians, $50 \%$ freshmen/sophomores, $53 \%$ state residents and $47 \%$ enrolled in Greek organisations. The majority of respondents were 20 years old or younger, lived off-campus and were single. Twenty-three per cent of respondents self-reported smoking in the past 30 days and were classified as current smokers. Nearly $60 \%$ of the sample reported being exposed to secondhand smoke on campus at least once in the past week, and almost $20 \%$ of the sample reported consuming alcohol at least 10 days in the past month. Women, minorities and students living on-campus were less likely to be current smokers, in bivariate analyses. In contrast, students enrolled in Greek houses were more likely to be current smokers.

Among the variables related to the campus smoke-free policy, $85 \%$ of respondents reported being aware of the campus smoking policy and more than $88 \%$ of respondents correctly chose smoke-free or tobacco-free as the campus policy. More than $63 \%$ of current smokers report ever smoking on campus, but less than $10 \%$ ever received a warning or a ticket for their violation. Nearly all respondents $(92.5 \%)$ reported witnessing someone smoking on campus, but only $22 \%$ reported witnessing someone receiving a ticket or warning for smoking on campus. Nearly three-fourths of the respondents reported being exposed to secondhand smoke on campus at least once and more than $25 \%$ of respondents reported altering their walk on campus to avoid smoke. Very few respondents reported witnessing none of the violations by others of the campus smoke-free policy $(6.3 \%$; table 1$)$. Overall, witnessing smoking policy violations by others was more likely to be reported by current smokers than nonsmokers. Specifically, current smokers were more likely to witness others smoking or receiving a ticket, but nonsmokers were more likely than current smokers to report altering their walk on campus to avoid smoke.

\section{Barriers to policy adherence}

Considering all respondents together, the most frequently cited barrier to a successful smoke-free campus policy was inadequate funding for implementation of the policy with $55.6 \%$ (840) of all respondents selecting strongly agree or agree (table 2). Other barriers receiving high levels of agreement from all respondents include difficulty to enforce $(40.4 \%, 611)$, lack of information about the policy $(37.4 \%, 565)$, lack of support from staff $(35.3 \%, 534)$ and faculty $(32.6 \%, 492)$, and lack of enforcement $(31.8 \%, 481)$. Current non-smokers 
Table 1 Characteristics of the study sample

\begin{tabular}{|c|c|c|c|c|}
\hline \multirow[b]{2}{*}{ Characteristic } & \multirow{2}{*}{$\begin{array}{l}\begin{array}{l}\text { Total } \\
\mathrm{n}=1512\end{array} \\
\mathrm{~N}(\%) \\
\end{array}$} & \multirow{2}{*}{$\begin{array}{l}\begin{array}{l}\text { Current smokers* } \\
\mathrm{n}=353\end{array} \\
\mathrm{~N}(\%)\end{array}$} & \multirow{2}{*}{$\begin{array}{l}\text { Current non-smokers } \\
n=1158\end{array}$} & \multirow[b]{2}{*}{$P$ value } \\
\hline & & & & \\
\hline Age & & & & 0.318 \\
\hline 18 to 20 & $957(64.5)$ & $213(61.2)$ & $744(65.6)$ & \\
\hline 21 to 24 & $491(33.1)$ & $125(35.9)$ & 365 (32.3) & \\
\hline $25+$ & $36(2.4)$ & $10(2.9)$ & $26(2.3)$ & \\
\hline Female & $904(60.9)$ & $114(32.8)$ & $789(69.5)$ & $<0.001$ \\
\hline Race & & & & $<0.001$ \\
\hline White & $1177(77.8)$ & $308(87.3)$ & $868(75.0)$ & \\
\hline Black & $179(11.8)$ & $12(3.4)$ & $167(14.4)$ & \\
\hline Non-black minorities & $156(10.3)$ & $33(9.3)$ & $123(10.6)$ & \\
\hline Past-smoker & $45(3.0)$ & $10(2.8)$ & $35(3.0)$ & 0.854 \\
\hline International student & $48(3.2)$ & $13(3.7)$ & $35(3.1)$ & 0.548 \\
\hline Resident of the state of Mississippi & $790(53.4)$ & $169(48.8)$ & $620(54.7)$ & 0.055 \\
\hline Greek membership & $711(47.9)$ & $185(53.2)$ & $525(46.3)$ & 0.025 \\
\hline Class year & & & & 0.226 \\
\hline Freshman & 295 (19.9) & $56(16.1)$ & $239(21.1)$ & \\
\hline Sophomore & $450(30.3)$ & $111(31.9)$ & $339(29.9)$ & \\
\hline Junior & $406(27.4)$ & $102(29.3)$ & $303(26.7)$ & \\
\hline Senior and above & $332(22.4)$ & $79(22.7)$ & $253(22.3)$ & \\
\hline Mean GPA (SD) & $3.19(0.48)$ & $3.06(0.47)$ & $3.23(0.48)$ & $<0.001$ \\
\hline On-campus housing & $493(33.2)$ & $91(26.1)$ & $402(35.4)$ & 0.001 \\
\hline Marital status & & & & 0.691 \\
\hline Single & $1422(95.9)$ & $334(96.3)$ & $1087(95.8)$ & \\
\hline Married/partnered & $44(3.0)$ & $8(2.3)$ & $36(3.2)$ & \\
\hline Divorced & $5(0.3)$ & $2(0.6)$ & $3(0.3)$ & \\
\hline Other & $12(0.8)$ & $3(0.9)$ & $9(0.8)$ & \\
\hline \multicolumn{2}{|c|}{ Frequency of alcohol consumption in past 30 days } & & & $<0.001$ \\
\hline None (0 days) & $298(20.1)$ & $11(3.2)$ & $287(25.4)$ & \\
\hline Low ( 1 to 6 days) & $529(35.8)$ & $72(20.7)$ & $456(40.4)$ & \\
\hline Medium (7 to 10 days) & $353(23.9)$ & $110(31.6)$ & $243(21.5)$ & \\
\hline High (more than 10 days) & $299(20.2)$ & $155(44.5)$ & $144(12.7)$ & \\
\hline \multicolumn{2}{|c|}{ Exposure to secondhand smoke on campus in past 7 days } & & & $<0.001$ \\
\hline 0 days & $616(40.8)$ & $142(40.3)$ & $474(41.0)$ & \\
\hline 1 to 3 days & $695(46.1)$ & $140(39.8)$ & $554(48.0)$ & \\
\hline 4 to 6 days & $117(7.8)$ & $33(9.4)$ & $84(7.3)$ & \\
\hline All 7 days & $80(5.3)$ & $37(10.5)$ & $43(3.7)$ & \\
\hline E-cigarette smoking frequency & & & & $<0.001$ \\
\hline Every day & $15(1.0)$ & $4(1.1)$ & $11(1.0)$ & \\
\hline Some day & $54(3.6)$ & $37(10.5)$ & $17(1.5)$ & \\
\hline Not at all & $1441(95.4)$ & $312(88.4)$ & $1129(97.6)$ & \\
\hline Self-reported awareness of smoking & & & & 0.002 \\
\hline Yes & $1291(85.4)$ & $322(91.2)$ & $968(83.6)$ & \\
\hline No & $67(4.4)$ & $11(3.1)$ & $56(4.8)$ & \\
\hline Not sure & $154(10.2)$ & $20(5.7)$ & $134(11.6)$ & \\
\hline
\end{tabular}




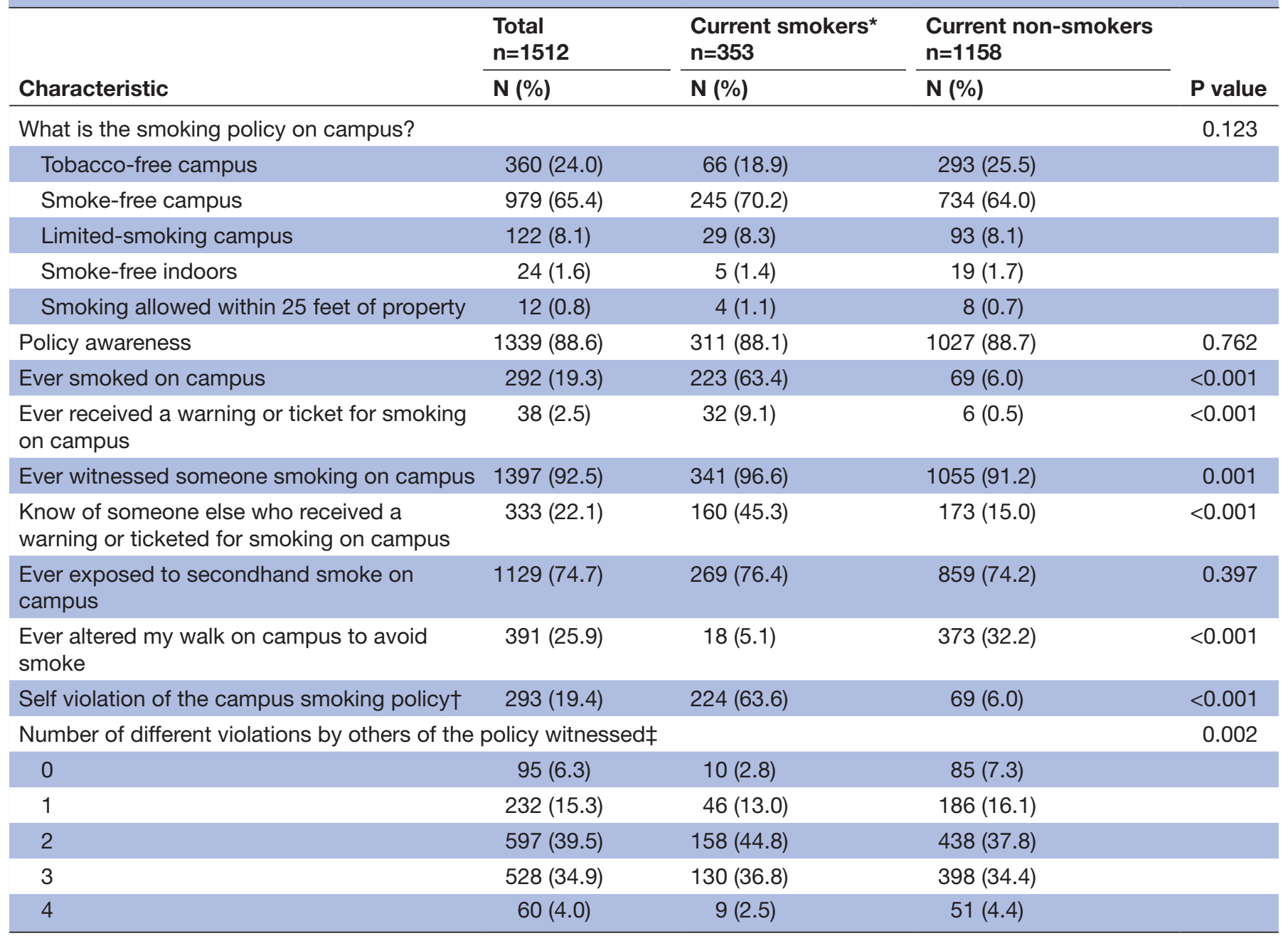

Percentages expressed in the table are based on denominators that exclude missing responses.

${ }^{*}$ Past 30-day user: Smoked at least one cigarette during the past 30 days.

†Self violation of the campus smoking policy was defined as either ever smoking on campus or receiving a warning or ticket for smoking on campus.

$\ddagger$ Number of different violations by others of the policy witnessed is the sum of four dichotomous items: ever witnessed someone smoking on campus, know of someone else who received a warning or ticketed for smoking on campus, ever exposed to secondhand smoke on campus and ever altered my walk on campus to avoid smoke.

GPA, grade point average.

rated six of the 11 barriers-inadequate funding, lack of information about the policy, lack of support from staff, infringement of personal freedoms, insufficient fines and lack of reminders-less frequently than past 30-day smokers. Only one barrier, difficult to enforce, received a lower agreement by past 30-day smokers compared to non-smokers.

\section{Smoke-free policy attitudes, smoking attitudes and policy support}

Using PCA, a two-factor solution was obtained for respondents' attitudes towards the smoke-free policy. The two factors, labelled 'policy adherence' and 'policy justification', had four items and two items each, with reliabilities (Cronbach's alpha) of 0.81 and 0.72 , respectively. On a scale of 1 to 5 , respondents rated policy adherence an average score of 2.6 (SD: 0.8 ), and policy justification an average score of 3.8 (SD: 0.9). A single-factor solution was obtained for both respondents' attitudes towards smoking (mean: 3.7; SD: 0.9; higher scores are indicative of negative attitudes towards smoking or positive attitudes about non-smoking behaviour) and support for the policy (mean: 3.8; SD: 1.1) with reliabilities of 0.89 and 0.85 , respectively. The factor loadings for each of the scales, along with the mean scores and SD for the total sample as well as for current (past 30-day) smokers and non-smokers, are provided in table 3.

\section{Factors predicting self-reported violation of the campus} smoke-free policy

In a logistic regression model predicting self-reported violation of the campus smoke-free policy (table 4), current 
Table 2 Student perceptions of barriers to a successful campus smoke-free policy

\begin{tabular}{|c|c|c|c|c|}
\hline Barrier & $\begin{array}{l}\text { Total } \\
\%(\mathbf{N})^{\star}\end{array}$ & $\begin{array}{l}\text { Current smokerst } \\
\%(\mathrm{~N})^{*}\end{array}$ & $\begin{array}{l}\text { Current non-smokers } \\
\%(\mathrm{~N})^{*}\end{array}$ & P value \\
\hline Inadequate funding & $55.6(840)$ & $62.0(219)$ & $53.6(621)$ & 0.005 \\
\hline Lack of information about policy & $37.4(565)$ & $42.8(151)$ & $35.8(414)$ & 0.017 \\
\hline Lack of support from staff & $35.3(534)$ & $49.9(176)$ & $30.9(358)$ & $<0.001$ \\
\hline Policy infringes on individuals' personal freedom & $27.5(415)$ & $39.1(138)$ & $23.9(277)$ & $<0.001$ \\
\hline Insufficient fines & $25.9(391)$ & $39.9(141)$ & $21.6(250)$ & $<0.001$ \\
\hline Lack of support from University administrators & $20.0(302)$ & $20.7(73)$ & $19.8(229)$ & 0.710 \\
\hline Lack of reminders about the policy & $16.0(242)$ & $24.6(87)$ & $13.4(155)$ & $<0.001$ \\
\hline
\end{tabular}

Barriers were measured using a 1 (not a barrier) to 5 (extreme barrier) response format.

*Percentage of respondents who selected strongly agree or agree.

†Past 30-day user: Smoked at least one cigarette during the past 30 days.

(past 30-day) smokers unsurprisingly are estimated to have at least five times the odds (OR: 7.96; 95\% CI: 5.13 to 12.36 ) of reporting that they had violated the policy compared to non-smokers and women had lower odds (OR: $0.36,95 \% \mathrm{CI}: 0.24$ to 0.55 ) of violating the policy compared to men. Stronger beliefs about policy adherence (OR: 0.52; 95\% CI: 0.40 to 0.69 ), greater support for the policy (OR: 0.71 ; $95 \%$ CI: 0.55 to 0.91 ), stronger attitudes against smoking behaviour (OR: 0.35; 95\% CI: 0.25 to 0.49$)$, and higher grade point average (GPA) (OR: $0.54 ; 95 \%$ CI: 0.35 to 0.82 ) were all related to lower odds of violating the policy. Non-black minorities (OR: 2.66; $95 \%$ CI: 1.28 to 5.51 ), on-campus residents (OR: 1.80; $95 \%$ CI: 1.02 to 3.16 ), in-state students (OR: 1.60; 95\% CI: 1.05 to 2.46 ) and students who reported a high frequency of alcohol consumption (OR: 2.49; 95\% CI: 1.17 to 5.31) had higher odds of violating the policy when compared with Caucasians, off-campus residents, out-ofstate students and students who reported not consuming any alcohol in the past 30 days, respectively. There were no significant interactions of past 30-day smoking status with any of the predictors in the model.

\section{DISCUSSION}

In an evaluation of adherence to a campus smoke-free policy, this study obtained a response rate of over $90 \%$ from a random sample of classes offered on campus. The undergraduate population on campus is composed of $55 \%$ females, $77 \%$ Caucasians, $30 \%$ freshmen, $20 \%$ sophomores, 22\% juniors, 28\% seniors and 42\% Greek organisation members, which closely approximates the distribution obtained in this study. ${ }^{36} 37$ An annual survey funded by the state Department of Health during the spring semester of 2016 found that $30.2 \%$ of respondents smoked at least one cigarette in the past 30 days which is higher than the $23 \%$ found in this study. ${ }^{38}$ The discrepancy in the prevalence estimates may be explained by the fact that the Department of Health funded survey had only a $7.3 \%$ response rate and included a nonrepresentative distribution of the student population. ${ }^{38}$ Nevertheless, the estimated $9.8 \%$ national prevalence of past 30-day smoking among undergraduate college students ${ }^{4}$ is much lower than the prevalence found in the current study comprised of University of Mississippi undergraduate students.

Overall, almost $90 \%$ of the respondents were aware of the campus smoking policy and nearly $20 \%$ reported violating the policy. The prevalence of self-reported policy violations was nearly $64 \%$ among current smokers and $6 \%$ among non-smokers (who have may been past smokers). Even though the survey was completely anonymous, it is possible that social desirability bias led to an underestimate of the prevalence of policy violations. An overwhelming majority of the respondents, $94 \%$, reported witnessing at least one violation of the campus smoke-free policy by others, implying that the policy has been largely unsuccessful. In line with expectations, respondents who believed the policy was effective had lower odds of violating the policy themselves. Self-reported policy violations were also associated with smoking behaviour and alcohol consumption, which is in line with the expectation that these risk behaviours often manifest concomitantly. ${ }^{39}$ Extant literature shows risk behaviours such as smoking tend to be associated with a lower GPA, ${ }^{4041}$ and this finding was corroborated in the current study. Neither membership in Greek organisations nor class year were related to self-reported policy violations. In this study, witnessing policy violations by others was reported at a higher rate than self-reporting them, indicating the possible role of social desirability bias in reporting policy violations. 
Table 3 Student attitudes towards smoking and the campus smoke-free policy

\begin{tabular}{|c|c|c|c|c|c|}
\hline Item & $\begin{array}{l}\text { Factor } \\
\text { loading }\end{array}$ & $\begin{array}{l}\text { Total } \\
\text { Mean (SD) }\end{array}$ & $\begin{array}{l}\text { Current smokers* } \\
\text { Mean (SD) }\end{array}$ & $\begin{array}{l}\text { Current non-smokers } \\
\text { Mean (SD) }\end{array}$ & $P$ value \\
\hline \multicolumn{6}{|c|}{ Student attitudes towards the campus smoke-free policies: Policy Adherence Subscale } \\
\hline The current policy is effective & 0.765 & $2.9(1.1)$ & $2.8(1.1)$ & $2.9(1.1)$ & 0.085 \\
\hline The current policy is enforced & 0.791 & $2.7(1.1)$ & $2.8(1.0)$ & $2.6(1.1)$ & 0.032 \\
\hline Most smokers comply with the current policy & 0.816 & $2.6(1.0)$ & $2.6(1.0)$ & $2.7(1.0)$ & 0.155 \\
\hline The current policy is ignored by smokers $†$ & 0.774 & $2.2(1.0)$ & $2.2(1.0)$ & $2.2(1.0)$ & 0.976 \\
\hline Total subscale score (alpha=0.81) & - & $2.6(0.8)$ & $2.6(0.8)$ & $2.6(0.8)$ & 0.746 \\
\hline \multicolumn{6}{|c|}{ Student attitudes towards the campus smoke-free policies: Policy Justification Subscale } \\
\hline The current policy is justified & 0.880 & $3.7(1.1)$ & $3.1(1.1)$ & $3.82(1.0)$ & $<0.001$ \\
\hline $\begin{array}{l}\text { The current policy helps create a healthy } \\
\text { environment }\end{array}$ & 0.857 & $3.9(1.0)$ & $3.6(1.0)$ & $4.0(1.0)$ & $<0.001$ \\
\hline Total subscale score (alpha=0.72) & - & $3.8(0.9)$ & $3.4(0.9)$ & $3.9(0.9)$ & $<0.001$ \\
\hline \multicolumn{6}{|l|}{ Student attitudes towards smoking } \\
\hline $\begin{array}{l}\text { If someone smokes cigarettes around } \\
\text { me they are causing me harm because of } \\
\text { secondhand smoke }\end{array}$ & 0.788 & $4.0(1.0)$ & $3.1(1.1)$ & $4.2(0.9)$ & $<0.001$ \\
\hline $\begin{array}{l}\text { I prefer to socialise in a smoke-free } \\
\text { environment }\end{array}$ & 0.867 & $4.0(1.1)$ & $3.0(1.0)$ & $4.3(0.9)$ & $<0.001$ \\
\hline I seek out smoke-free environments & 0.871 & $3.5(1.3)$ & $2.4(1.0)$ & $3.8(1.1)$ & $<0.001$ \\
\hline $\begin{array}{l}\text { It disappoints me when a friend who normally } \\
\text { doesn't smoke, smokes cigarettes while } \\
\text { drinking }\end{array}$ & 0.821 & $3.4(1.3)$ & $2.1(1.0)$ & $3.8(1.2)$ & $<0.001$ \\
\hline I would rather date a non-smoker & 0.693 & $4.4(0.9)$ & $3.7(1.1)$ & $4.6(0.7)$ & $<0.001$ \\
\hline I ask others not to smoke around me & 0.795 & $3.1(1.3)$ & $2.0(1.1)$ & $3.4(1.3)$ & $<0.001$ \\
\hline Total scale score (alpha=0.89) & - & $3.7(0.9)$ & $2.7(0.7)$ & $4.0(0.8)$ & $<0.001$ \\
\hline \multicolumn{6}{|c|}{ Student support for the campus smoke-free policy } \\
\hline $\begin{array}{l}\text { Smoking should be banned in all university } \\
\text { buildings }\end{array}$ & 0.643 & $4.5(0.9)$ & $4.1(1.2)$ & $4.6(0.8)$ & $<0.001$ \\
\hline $\begin{array}{l}\text { Smoking should be banned on all university } \\
\text { property }\end{array}$ & 0.874 & $3.6(1.3)$ & $2.5(1.3)$ & 4.0 (1.2) & $<0.001$ \\
\hline $\begin{array}{l}\text { All tobacco products should be banned in all } \\
\text { university buildings }\end{array}$ & 0.867 & 3.7 (1.4) & $2.9(1.5)$ & $4.0(1.2)$ & $<0.001$ \\
\hline $\begin{array}{l}\text { All tobacco products should be banned on all } \\
\text { university property }\end{array}$ & 0.900 & $3.2(1.4)$ & $2.2(1.2)$ & $3.5(1.3)$ & $<0.001$ \\
\hline Total scale score (alpha=0.85) & - & $3.8(1.1)$ & $2.9(1.0)$ & $4.0(1.0)$ & $<0.001$ \\
\hline
\end{tabular}

All items were measured using a 1 (strongly disagree) to 5 (strongly agree) response format.

*Past 30-day user: Smoked at least one cigarette during the past 30 days.

†This item was reverse coded prior to calculation of the scale score.

This study found that, despite high levels of policy awareness, smoke-free policies are largely ineffective at curtailing smoking behaviour on university campuses. The ineffectiveness of the policy was reflected in the fact that nearly $75 \%$ of respondents have been exposed to secondhand smoke on campus, which is the primary purpose of a smoke-free policy. The most significant barrier to a successful smoke-free campus policy was the lack of adequate funding and the difficulty of enforcing the policy. However, smokers and non-smokers highlighted different barriers. Smokers rated both inadequate funding and lack of support from staff very highly, while non-smokers acknowledged the difficulty in enforcing the law much more frequently than smokers. The other highly rated barriers to success, lack of information, lack of support from staff and faculty, and lack of enforcement also indicate a lack of buy-in for policy enforcement. The results of this study must be interpreted in the context of these limited enforcement efforts. Less than $3 \%$ of respondents received a ticket, while nearly $20 \%$ reported violating the policy. This discrepancy suggests a greater need for reminders which might not be necessary 
Table 4 Logistic regression results predicting self-violation of campus smoke-free policy

\begin{tabular}{|c|c|c|}
\hline \multirow[b]{2}{*}{ Characteristic } & \multicolumn{2}{|c|}{$\begin{array}{l}\text { Violation of the campus } \\
\text { smoke-free policy }\end{array}$} \\
\hline & $\begin{array}{l}\text { Adjusted OR } \\
(95 \% \mathrm{Cl})\end{array}$ & $P$ value \\
\hline Current smoker* & 7.96 (5.13 to 12.36$)$ & $<0.001$ \\
\hline Policy Adherence Subscale & 0.52 (0.40 to 0.69$)$ & $<0.001$ \\
\hline Policy Justification Subscale & 0.98 (0.76 to 1.27$)$ & 0.898 \\
\hline Smoking Attitudes Scale & 0.35 (0.25 to 0.49$)$ & $<0.001$ \\
\hline Policy Support Scale & 0.71 (0.55 to 0.91$)$ & 0.008 \\
\hline Policy awareness & 1.24 (0.68 to 2.25$)$ & 0.486 \\
\hline Female & $0.36(0.24$ to 0.55$)$ & $<0.001$ \\
\hline \multicolumn{3}{|l|}{ Age } \\
\hline 18 to 20 years & Reference & \\
\hline 21 to 24 years & 0.76 (0.41 to 1.42$)$ & 0.386 \\
\hline 25 and older & 0.93 (0.24 to 3.62$)$ & 0.917 \\
\hline \multicolumn{3}{|l|}{ Race } \\
\hline Caucasian & Reference & \\
\hline African-American & 1.42 (0.69 to 2.89$)$ & 0.339 \\
\hline Other minorities & 2.66 (1.28 to 5.51$)$ & 0.009 \\
\hline Resident of Mississippi & 1.60 (1.05 to 2.46$)$ & 0.031 \\
\hline International & 1.58 (0.52 to 4.79$)$ & 0.420 \\
\hline Greek membership & 1.21 (0.78 to 1.88$)$ & 0.401 \\
\hline \multicolumn{3}{|l|}{ Class year } \\
\hline Freshman & Reference & \\
\hline Sophomore & 1.45 (0.70 to 2.99$)$ & 0.316 \\
\hline Junior & 1.60 (0.72 to 3.56$)$ & 0.250 \\
\hline Senior and above & 2.26 (0.88 to 5.79$)$ & 0.091 \\
\hline GPA & 0.54 (0.35 to 0.82$)$ & 0.004 \\
\hline On campus residence & 1.80 (1.02 to 3.16$)$ & 0.042 \\
\hline \multicolumn{3}{|l|}{ Frequency of alcohol use } \\
\hline None & Reference & \\
\hline Low & 1.24 (0.60 to 2.54$)$ & 0.563 \\
\hline Medium & 1.77 (0.83 to 3.75$)$ & 0.139 \\
\hline High & 2.49 (1.17 to 5.31$)$ & 0.018 \\
\hline
\end{tabular}

*Past 30-day user: Smoked at least one cigarette during the past 30 days.

GPA, grade point average.

on campuses where the policy is strictly enforced. The measurement of barriers also shows that many respondents believe it was important to have support from students, faculty and administrators in order to implement the policy. While the nature of this support was not defined as part of the survey, it appears that most respondents believe the entire campus community needs to buy-in in order to successfully implement this policy. This community support may be in the form of students and faculty discouraging campus smoking behaviour, peer approval and social norms, among others.
Contrary to expectations from previous research, ${ }^{1721} 2642$ the prevalence of smoking on campus may have increased since the implementation of the campus smoke-free policy in 2012. ${ }^{38}$ The rising prevalence of smoking and the frequency of policy violations suggest the need for a renewed strategy of policy enforcement. Universities willing to enact or enforce campus smoke-free policies must focus on creating an environment where policy violations are not tolerated, and the administration, faculty and students support the ban on smoking in public places. Strategies to achieve this environment might include strict ticketing policies, strategically placed reminder signs, reinforcement of student beliefs about smoking and overall policy support which were found to be important predictors of policy violation in this study. Further attention must be paid to campus alcohol consumption and social or sporting events where violations of policy might be more prevalent.

While some researchers have sought to stress the importance of education campaigns, the high rates of policy awareness and generally strong attitudes against smoking behaviour found in this study imply that educational campaigns addressing the policy or the hazards of tobacco use might not necessarily be effective at improving policy compliance. ${ }^{182643}$ On the other hand, there is much support in the literature on the potential of strong enforcement policies in decreasing smoking prevalence. ${ }^{1422}$ Harris and colleagues recommend the use of passive techniques such as reminder signs about the smoke-free policy, along with more active strategies such as direct contact with violators using volunteers to improve engagement, periodic positive reinforcement and hosting interactive compliance events to serve as additional reminders. ${ }^{22}$

While this study provides critical evidence to support development strategies to improve campus smoke-free policy compliance, it also carries some limitations. Even though the survey had a 90\% response rate among invited students, only $50 \%$ of invited instructors agreed to participate in the study. While many instructors did not choose to participate, because instructor choices are not expected to be related to smoking behaviour among their students, this is not expected to bias the study's findings. This study used self-report to identify smoking behaviour and policy violations. Both these behaviours can be under-reported due to a combination of social desirability bias and recall bias. This study also did not delineate the use of e-cigarettes from regular cigarettes, or capture frequency of policy violations specifically associated with the use of e-cigarettes; rather, the questions simply referred to 'smoking on campus'. It is possible that many respondents might have a misunderstanding of whether smoke-free policies include a ban on use of e-cigarettes (even though the policy clearly specifies that e-cigarettes are included in the ban) ${ }^{28}$ thereby leading to a bias in the estimate of policy violations. Similarly, individuals who incorrectly believed the campus was tobacco-free as opposed to smoke-free might have different perceptions 
of barriers or their support for the policy because of their incorrect understanding of what is included in the policy. These differences were not explored in the current study. It is important to recognise that this is an observational study and there are correlations among the predictor variables. The logistic regression model estimated in this study can help to identify possible predictors of policy violations. Future research is necessary to evaluate the meaningfulness of these predictors and whether they can be targeted for possible intervention to reduce violations. Finally, although a large sample was obtained, these data were collected 4 years ago, and although there is no reason to expect so, some of these findings may have changed since then. In addition, this study only included policy violations by smoking and did not assess other behaviours such as littering or possession of tobacco products, as mentioned in the policy. Policy violations were also only assessed in students, whereas such violations could have been committed by staff, employees or visitors. The findings of this study must also be interpreted in the context of the campus where this study was conducted; thus, generalisation to other universities must be made with caution.

\section{CONCLUSION}

This study found that violations of a campus smokefree policy are fairly common. Policy violations might be related to smoking behaviour, beliefs about policy adherence, smoking attitudes and support for the policy. Important barriers to policy adherence include a lack of reminders about the policy, lack of student and administrative support, and a need for stricter policy enforcement. Additional interventions are needed to improve compliance with the policy and reduce prevalence of smoking on campus.

\section{Twitter Sujith Ramachandran @ramasujith}

Contributors SB and JB designed the survey and the data collection procedure. Data collection and data entry was coordinated by SB and EC. Data analysis was conducted by SR and JB. All authors contributed to the interpretation of results and manuscript preparation. All authors read and approved the final manuscript.

Funding The authors have not declared a specific grant for this research from any funding agency in the public, commercial or not-for-profit sectors.

Competing interests None declared.

Patient consent for publication Not required.

Ethics approval This study was approved by the University of Mississippi Institutional Review Board (UM IRB) before data were collected (Protocol \#16x011). Respondents provided consent to participate by completing the paper-based survey (this approach to consent was approved by the UM IRB and a statement was included on the front of the survey booklet that stated, "By completing the survey, I consent to participate in the study").

\section{Provenance and peer review Not commissioned; externally peer reviewed.}

Data availability statement Data are available upon reasonable request. The datasets used and/or analysed during the current study are available from the corresponding author on reasonable request.

Open access This is an open access article distributed in accordance with the Creative Commons Attribution Non Commercial (CC BY-NC 4.0) license, which permits others to distribute, remix, adapt, build upon this work non-commercially, and license their derivative works on different terms, provided the original work is properly cited, appropriate credit is given, any changes made indicated, and the use is non-commercial. See: http://creativecommons.org/licenses/by-nc/4.0/.

\section{ORCID iD}

Sujith Ramachandran http://orcid.org/0000-0002-8792-4307

\section{REFERENCES}

1 Centers for Disease Control and Prevention (CDC). Current cigarette smoking among adults - United States, 2011. MMWR Morb Mortal Wkly Rep 2012;61:889-94.

2 Wechsler H, Rigotti NA, Gledhill-Hoyt J, et al. Increased levels of cigarette use among college students: a cause for national concern. JAMA 1998;280:1673-8.

3 National Center for Chronic Disease Prevention and Health Promotion (US) Office on Smoking and Health. The Health Consequences of Smoking - 50 Years of progress: A Report of the Surgeon General. Atlanta, GA: Centers for Disease Control and Prevention (US), 2014.

4 American College Health Association. National College health assessment II: reference group executive summary spring 2015, 2015. Available: https://www.acha.org/documents/ncha/NCHA-II FALL_2015_UNDERGRADUATE_REFERENCE_GROUP_EXECUTIVE SUMMARY.pdf [Accessed 15 Jul 2019].

5 American College Health Association. National College health assessment II: reference group executive summary spring 2018, 2018. Available: https://www.acha.org/documents/ncha/NCHA-II Fall_2018_Undergraduate_Reference_Group_Executive_Summary. pdf [Accessed 15 Jul 2019].

6 American College Health Association. ACHA guidelines: position statement on tobacco on college and university campuses. Hanover, MD: American College Health Association, 2009.

7 Loukas A, Garcia MR, Gottlieb NH. Texas college students' opinions of no-smoking policies, secondhand smoke, and smoking in public places. J Am Coll Health 2006;55:27-32.

8 Burns S, Jancey J, Bowser N, et al. "Moving forward: a cross sectional baseline study of staff and student attitudes towards a totally smoke free university campus". BMC Public Health 2013;13:738.

9 Niemeier BS, Chapp CB, Henley WB. Improving tobacco-free advocacy on College campuses: a novel strategy to aid in the understanding of student perceptions about policy proposals. J Am Coll Health 2014;62:498-505.

10 Rigotti NAet al. Students' opinion of tobacco control policies recommended for us colleges: a national survey. Tob Control 2003;12:251-6.

11 Thompson B, Coronado GD, Chen L, et al. Preferred smoking policies at 30 Pacific Northwest colleges. Public Health Rep 2006;121:586-93.

12 Berg CJ, Lessard L, Parelkar PP, et al. College student reactions to smoking bans in public, on campus and at home. Health Educ Res 2011;26:106-18.

13 NR Foundation for the people. Colleges and universities with smokefree and tobacco-free policies, 2014.

14 Fennell R. Should College campuses become tobacco free without an enforcement plan? J Am Coll Health 2012;60:491-4.

15 Russette HC, Harris KJ, Schuldberg D, et al. Policy compliance of smokers on a tobacco-free university campus. J Am Coll Health 2014;62:110-6.

16 Fallin A, Murrey M, Johnson AO, et al. Measuring compliance with tobacco-free campus policy. J Am Coll Health 2012;60:496-504.

17 Lechner WV, Meier E, Miller MB, et al. Changes in smoking prevalence, attitudes, and beliefs over 4 years following a campuswide anti-tobacco intervention. J Am Coll Health 2012;60:505-11.

18 Borders TF, Xu KT, Bacchi D, et al. College campus smoking policies and programs and students' smoking behaviors. BMC Public Health 2005;5:74.

19 Baillie L, Callaghan D, Smith ML. Canadian campus smoking policies: investigating the gap between intent and outcome from a student perspective. J Am Coll Health 2011;59:260-5.

20 Fallin A, Roditis M, Glantz SA. Association of campus tobacco policies with secondhand smoke exposure, intention to smoke on campus, and attitudes about outdoor smoking restrictions. Am J Public Health 2015;105:1098-100.

21 Seo D-C, Macy JT, Torabi MR, et al. The effect of a smoke-free campus policy on college students' smoking behaviors and attitudes. Prev Med 2011;53:347-52.

22 Harris KJ, Stearns JN, Kovach RG, et al. Enforcing an outdoor smoking ban on a College campus: effects of a multicomponent approach. J Am Coll Health 2009;58:121-6. 
23 Hahn EJ, Fallin A, Darville A, et al. The three Ts of adopting tobacco-free policies on College campuses. Nurs Clin North Am 2012;47:109-17.

24 Glassman TJ, Reindl DM, Whewell AT. Strategies for implementing a tobacco-free campus policy. J Am Coll Health 2011;59:764-8.

25 Thrasher JF, Boado M, Sebrié EM, et al. Smoke-Free policies and the social acceptability of smoking in Uruguay and Mexico: findings from the International tobacco control policy evaluation project. Nicotine Tob Res 2009;11:591-9.

26 Chaaya M, Alameddine M, Nakkash R, et al. Students' attitude and smoking behaviour following the implementation of a university smoke-free policy: a cross-sectional study. BMJ Open 2013;3:e002100.

27 Fong GT, Cummings KM, Borland R, et al. The conceptual framework of the International tobacco control (ITC) policy evaluation project. Tob Control 2006;15(Suppl 3):iii3-11.

28 University of Mississippi. Smoke-free policy, 2016. Available: https:// policies.olemiss.edu/ShowDetails.jsp?istatPara=1\&policyObjidPara= 11524920 [Accessed 15 Jul 2019].

29 Tracy JJ, Lombardo TW, Bentley JP. A smoker identity measure for experimental, intermittent, and daily college student smokers. Am J Health Promot 2012;27:55-62.

30 Jamal A, King BA, Neff LJ, et al. Current cigarette smoking among adults - United States, 2005-2015. MMWR Morb Mortal Wkly Rep 2016;65:1205-11.

31 Arrazola RA, Singh T, Corey CG, et al. Tobacco use among middle and high school students - United States, 2011-2014. MMWR Morb Mortal Wkly Rep 2015;64:381.

32 Berg CJ, Lust KA, Sanem JR, et al. Smoker self-identification versus recent smoking among college students. Am J Prev Med 2009;36:333-6.

33 National Center for Chronic Disease Prevention and Health Promotion (US) Office on Smoking and Health. Preventing tobacco use among youth and young adults: a report of the surgeon
General. Atlanta, GA: Centers for Disease Control and Prevention (US), 2012

34 Shore TH, Tashchian A, Adams JS. Development and validation of a scale measuring attitudes toward smoking. J Soc Psychol 2000;140:615-23.

35 Jancey J, Bowser N, Burns S, et al. No smoking here: examining reasons for noncompliance with a smoke-free policy in a large university. Nicotine Tob Res 2014;16:976-83.

36 University of Mississippi. Fraternity Sorority Academic Report Fall 2015, 2015. Available: http://greeks.olemiss.edu/wp-content/ uploads/sites/42/2017/05/UM-Fraternity-Sorority-Academic-ReportFall-2015.pdf [Accessed 15 Jul 2019].

37 University of Mississippi. Mini fact book 2014-2015, 2015. Available: https://universityplanning.wp.olemiss.edu/wp-content/uploads/sites/ 98/2015/04/Mini-Fact-Book-2014-15-FINAL.pdf [Accessed 15 Jul 2019].

38 University of Mississippi. University survey of tobacco control, 2016. Available: https://mstobaccodata.org/wp-content/uploads/2015/08/ 2016-university-report-um.pdf [Accessed 15 Jul 2019].

39 Moran S, Wechsler H, Rigotti NA. Social smoking among US college students. Pediatrics 2004:114:1028-34.

40 Cox RG, Zhang L, Johnson WD, et al. Academic performance and substance use: findings from a state survey of public high school students. J Sch Health 2007;77:109-15.

41 Tucker JS, Martínez JF, Ellickson PL, et al. Temporal associations of cigarette smoking with social influences, academic performance, and delinquency: a four-wave longitudinal study from ages 13-23. Psychol Addict Behav 2008;22:1-11.

42 Wechsler H, Lee JE, Rigotti NA. Cigarette use by college students in smoke-free housing: results of a national study. Am J Prev Med 2001;20:202-7.

43 Bennett BL, Deiner M, Pokhrel P. College anti-smoking policies and student smoking behavior: a review of the literature. Tob Induc Dis 2017;15:11 